\title{
Multiple Personality Disorder: Am I Physician or Son?
}

\section{Elie EI Rassy MD}

Hotel Dieu de France University Hospital; Faculty of Medicine, Saint Joseph University Beirut, Lebanon

${ }^{*}$ Corresponding author: Elie El Rassy MD, Hotel Dieu de France University Hospital, Faculty of Medicine, Saint Joseph University Beirut, Lebanon, Tel: 009611615300; E-mail: elie.rassy@hotmail.com

Receiving date: April 29 2015; Accepted date: May 23 2015; Published date: May 272015

Copyright: $\odot 2015$ Rassy E. This is an open-access article distributed under the terms of the Creative Commons Attribution License, which permits unrestricted use, distribution, and reproduction in any medium, provided the original author and source are credited.

\begin{abstract}
Throughout history, several types of relationships joined physicians to patients: trust, skepticism, paternalism and autonomy. However, family-physician relationship is the most difficult to handle. The best approach to this dilemma would be for the clinician to ask the ill family member for his expectations and accommodate for the satisfaction of both.
\end{abstract}

\section{Dear Editor,}

It is not till recently that I realized a forgotten medical dilemma that physicians may counterface as part of their daily lives. This dilemma cannot be subsided by leaving the clinics. On the contrary, it would follow us home and even haunt our beds. I recently graduated from a local medschool in Lebanon. It is a poor Middle Eastern country with very limited resources. Medical services are not an exception. Lebanon, as most of the societies of this geographic zone, is characterized by very tight and close family bonds. These families consider having a graduated physician from a well named university a health salvation. This is how I got referrals, phone calls and e-mails of relatives I have never heard from. However, my dilemma rose when my mother got sick and my medical knowledge shattered my personality to multiple personalities: son and/or physician.

My medical curriculum initiated me to break bad news, to listen and to perceive cues and concerns. But it never addressed this dilemma. Its sole approach was to discourage ones medical care for their own families based on a publication in 1803 by Percival. It augmented that professional objectivity compromised resulting in increased testing and decreased cost-effectiveness. I reproach Percival that he did not take into consideration the complexity and errors of our health systems. These medical ethics do not stand when confronting real-world dilemmas.

Abandoning either personality was not an option. As a family member, I am knowledgeable about my mother's preferences. Whilst as a physician, I am better knowing of her medical history than any of the medical staff. Moreover, other family members turned to me for help expecting a rigorous follow up, desiring more information, challenging my clinician's role and turning me into an information provider. Albeit my colleague physicians admit the presence of a huge difficulty in balancing between the two personalities, they did not make the task any easier. At some point they were dependent of my follow up of the labs and recommended me for advising my mother of the adequate care and better referrals. However, some circumstances required my intervention probably because of my excessive attention to details that seen retrospectively are of unimportant significance.

Looking backwards, a "physician-son" would look up more for the emotions, needs, desires, expectations and deceptions of his ill family member. He would ensure the patient's safety and minimizes the risks. He would perceive before the patient claims to need. Physicians across specialties, especially males, were found to focus away from emotions and unrecognizing to patient-initiated cues and concerns. Moreover, safety and risk are tolerated differently by each physician and empathy was shown to decrease along the medical education.

Throughout history, several types of relationships joined physicians to patients: trust, skepticism, paternalism and autonomy. However, family-physician relationship is the most difficult to handle. After experiencing it, the best approach to this multiple personality disorder would have been probably for the clinician to ask the ill family member for his expectations and accommodate for the satisfaction of both. But personally, I am more prone to be involved. 